\title{
Actinobacillus succinogenes ATCC 55618 Fermentation Medium Optimization for the Production of Succinic Acid by Response Surface Methodology
}

\author{
Li-Wen Zhu, ${ }^{1}$ Cheng-Cheng Wang, ${ }^{1,2}$ Rui-Sang Liu, ${ }^{1}$ Hong-Mei Li, ${ }^{1}$ \\ Duan-Ji Wan, ${ }^{1}$ and Ya-Jie Tang ${ }^{1,2,3}$ \\ ${ }^{1}$ Key Laboratory of Fermentation Engineering (Ministry of Education), Hubei University of Technology, Wuhan 430068, China \\ ${ }^{2}$ Wuhan Institute of Virology, Chinese Academy of Sciences, Wuhan 430071, China \\ ${ }^{3}$ State Key Laboratory of Bioreactor Engineering, East China University of Science and Technology, 130 Meilong Road, \\ Shanghai 200237, China
}

Correspondence should be addressed to Ya-Jie Tang, yajietang@hotmail.com

Received 31 March 2012; Revised 29 May 2012; Accepted 8 June 2012

Academic Editor: Guihua H. Bai

Copyright ( 2012 Li-Wen Zhu et al. This is an open access article distributed under the Creative Commons Attribution License, which permits unrestricted use, distribution, and reproduction in any medium, provided the original work is properly cited.

\begin{abstract}
As a potential intermediary feedstock, succinic acid takes an important place in bulk chemical productions. For the first time, a method combining Plackett-Burman design (PBD), steepest ascent method (SA), and Box-Behnken design (BBD) was developed to optimize Actinobacillus succinogenes ATCC 55618 fermentation medium. First, glucose, yeast extract, and $\mathrm{MgCO}_{3}$ were identified to be key medium components by PBD. Second, preliminary optimization was run by SA method to access the optimal region of the key medium components. Finally, the responses, that is, the production of succinic acid, were optimized simultaneously by using BBD, and the optimal concentration was located to be $84.6 \mathrm{~g} \mathrm{~L}^{-1}$ of glucose, $14.5 \mathrm{~g} \mathrm{~L}^{-1}$ of yeast extract, and $64.7 \mathrm{~g} \mathrm{~L}^{-1}$ of $\mathrm{MgCO}_{3}$. Verification experiment indicated that the maximal succinic acid production of $52.7 \pm 0.8 \mathrm{~g} \mathrm{~L}^{-1}$ was obtained under the identified optimal conditions. The result agreed with the predicted value well. Compared with that of the basic medium, the production of succinic acid and yield of succinic acid against glucose were enhanced by $67.3 \%$ and $111.1 \%$, respectively. The results obtained in this study may be useful for the industrial commercial production of succinic acid.
\end{abstract}

\section{Introduction}

Succinic acid is a member of the four-carbon dicarboxylic acid family in tricarboxylic acid cycle (TCA) and has a wide range of applications in the fields of surfactants, green solvents, and pharmaceutical intermediates as an important four-carbon intermediate compound [1]. Succinic acid is classified as the most promising chemical among 12 biobased chemicals by the U.S. Department of Energy [2]. Succinic acid has been conventionally produced from fossil raw materials for more than a century, which can lead to high cost, feedstock exhaustion, and environment pollution [3, 4]. Recent studies suggest that the production of succinic acid by microbe fermentation has the potential to solve the aforementioned problems [5].

As the endproduct of energy metabolism, succinic acid can be produced by many anaerobic microbes, such as
Actinobacillus succinogenes, Anaerobiospirillum succiniciproducens, Mannheimia succiniciproducens, and Escherichia coli especially A. succinogenes ATCC 55618, which is a facultative anaerobe isolated from the bovine rumen [6]. It could produce higher concentration succinic acid as a major endproduct than other strains without gene reconstruction and glucose feeding [7]. However, to obtain a high production of succinic acid (i.e., more than $45 \mathrm{~g} \mathrm{~L}^{-1}$ ), the fermentation medium compositions were often complicated with the addition of high concentration of glucose and ten kinds of slight vitamins [8-10]. According to the aforementioned reports, about twenty kinds of components were added into the fermentation medium for the succinic acid production, which led to high cost and complex operation. It must be paid attention that the complicated medium is not the assurance of high production of succinic acid [11-13]. So 
the optimization of fermentation medium of $A$. succinogenes ATCC 55618 is essential.

Since nine components existed in the fermentation medium (i.e., glucose, yeast extract (YE), corn steep liquor (CSL), $\mathrm{KH}_{2} \mathrm{PO}_{4}, \mathrm{~K}_{2} \mathrm{HPO}_{4}, \mathrm{NaCl}, \mathrm{MgCl}_{2}, \mathrm{CaCl}_{2}$, and $\mathrm{MgCO}_{3}$ ), a great number of experiments should be simultaneously run, and the possible interactions between these components were also needed to be studied. For fermentation medium optimization, Plackett-Burman design (PBD) was a good choice in rapid screening multifactors to find the most significant independent factors [14]. Moreover, to optimize the concentration of the important factors, statistical methods have been done by using response surface methodology (RSM), in which several factors were simultaneously varied [15]. Compared with the one-factorat-a-time method, statistical experimental design has the advantages of reducing experiment numbers and improving statistical interaction analysis [16-18]. For the reasons above, we proposed the optimization method including the following steps: (1) using a two-level PBD to identify the key medium components and their experimental levels for further optimization, (2) applying the path of steepest ascent (SA) to move rapidly towards the neighborhood of the optimum response, and (3) employing a Box-Behnken design (BBD) to develop mathematical models to estimate the relationships between the response (i.e., the succinic acid production) and the key components.

\section{Materials and Methods}

2.1. Maintenance and Preculture of A. succinogenes ATCC 55618. The strain of A. succinogenes ATCC 55618, purchased from American Type Culture Collection (ATCC), was maintained in $20 \%$ glycerol at $-70^{\circ} \mathrm{C}$.

The plate was inoculated with the strain maintained at $-70^{\circ} \mathrm{C}$ and incubated at $37^{\circ} \mathrm{C}$ for 2 days. Preculture medium consisted of the following components $\left(\mathrm{g} \mathrm{L}^{-1}\right)$ : tryptone 17 ; soya peptone 3; glucose 2.5; $\mathrm{NaCl} 5 ; \mathrm{K}_{2} \mathrm{HPO}_{4} 2.5$. The culture $\mathrm{pH}$ was adjusted to 7.5. For the first preculture, $50 \mathrm{~mL}$ of medium was prepared in a $250-\mathrm{mL}$ anaerobic bottle, and a colony from a plate culture was inoculated, and then incubated for 12 hours at $37^{\circ} \mathrm{C}$ on a rotary shaker at $120 \mathrm{rpm}$. For the second preculture, $47.5 \mathrm{~mL}$ of medium was prepared in a $250-\mathrm{mL}$ anaerobic bottle, inoculated with $2.5 \mathrm{~mL}$ of the first preculture broth, and incubated for 12 hours at $37^{\circ} \mathrm{C}$ on a rotary shaker at $120 \mathrm{rpm}$.

2.2. Fermentation Process. Basic fermentation medium with an initial $\mathrm{pH}$ of 7.0 was composed of $\left(\mathrm{g} \mathrm{L}^{-1}\right)$ : glucose 107; yeast extract (YE) 16; corn steep liquor (CSL) 12; $\mathrm{KH}_{2} \mathrm{PO}_{4}$ 3; $\mathrm{K}_{2} \mathrm{HPO}_{4}$ 1.5; $\mathrm{NaCl} 1 ; \mathrm{MgCl}_{2}$ 0.3; $\mathrm{CaCl}_{2} 0.3 ; \mathrm{MgCO}_{3} 40$. The fermentation medium was inoculated with $2.5 \mathrm{~mL}$ of the second preculture broth in $47.5 \mathrm{~mL}$ of medium in a $250-\mathrm{mL}$ anaerobic bottle with $\mathrm{CO}_{2}$ as the gas phase. The fermentation was incubated at $37^{\circ} \mathrm{C}$ on a rotary shaker at $180 \mathrm{rpm}$. The dynamic profile of the succinic acid biosynthesis of $A$. succinogenes was monitored during the submerged fermentation process. Three flasks were taken each time for sampling. Each data point was expressed by an average with an error bar (i.e., standard error from three independent samples).

2.3. Plackett-Burman Design (PBD). The purpose of Plackett-Burman design (PBD) was to identify the key medium components for the succinic acid production. Table 1 shows the PBD used in this study [19]. Two dummy variables, whose levels did not change in the design, were introduced to estimate the population standard error. The first order was used to fit data from PBD as follows:

$$
Y=\beta_{0}+\sum \beta_{i} x_{i}
$$

where $Y$ is the predicted response, $\beta_{0}$ and $\beta_{i}$ are constant coefficients, and $x_{i}$ is the coded independent factors. Analysis for the PBD was carried out as follows.

First, the effect of all variables, including dummies, was calculated as follows:

$$
E_{v i}=\frac{\sum R_{v i(+)}-\sum R_{v i(-)}}{N / 2},
$$

where $E_{v i}$ is the effect of variable $i ; R_{v i(+)}$ and $R_{v i(-)}$ represent the response parameter (i.e., the succinic acid production) of an assembly in the screening design which contains the high and low levels of variable $i$, respectively; $N$ is the number of assemblies (in this study, $N=12$ ).

After determining the effect of each variable, the standard deviation (SD) of dummies, which serves as the population standard deviation in the Student's $t$-test as follows was calculated:

$$
\mathrm{SD}=\sqrt{\frac{\sum\left(E_{d}\right)^{2}}{n}},
$$

where $E_{d}$ is the effect of dummy variables; $n$ is the number of dummy variables (in this study, $n=2$ ).

Finally, a Student's $t$-test was performed to identify the significant $t$ factors as follows:

$$
t_{v i}=\frac{E_{v i}}{\mathrm{SD}}
$$

The variable which has no effect will give a $t$-value of 0 . The larger the absolute value of the $t$-value, the variable is more significant.

2.4. Steepest Ascent (SA). The method of steepest ascent (SA) design was used to move rapidly towards the neighborhood of the optimum response. Table 2 shows the SA used in this study. The experiments were adopted to determine a suitable direction by increasing or decreasing the concentrations of variables according to the results of PBD [20].

2.5. Box-Behnken Design (BBD). A 15-run Box-Behnken design (BBD) with three center points was employed in this work, and the maximal values of the productions of succinic acid were shown in Table 3.

To describe the relationships between the succinic acid production and the medium components, a mathematical 
TABle 1: The Plackett-Burman design experiment design matrix ${ }^{\mathrm{a}}$ and experimental results.

\begin{tabular}{|c|c|c|c|c|c|c|c|c|c|c|c|}
\hline \multirow{2}{*}{ Runs } & \multicolumn{9}{|c|}{ Variables $\left(\mathrm{g} \mathrm{L}^{-1}\right)$} & \multirow{2}{*}{$\mathrm{OD}_{660}$} & \multirow{2}{*}{ Succinic acid production $\left(\mathrm{g} \mathrm{L}^{-1}\right)$} \\
\hline & Glucose & $\mathrm{YE}^{\mathrm{b}}$ & $\mathrm{CSL}^{\mathrm{c}}$ & $\mathrm{K}_{2} \mathrm{HPO}_{4}$ & $\mathrm{KH}_{2} \mathrm{PO}_{4}$ & $\mathrm{NaCl}$ & $\mathrm{MgCl}_{2}$ & $\mathrm{CaCl}_{2}$ & $\mathrm{MgCO}_{3}$ & & \\
\hline 1 & 80.0 & 15.0 & 15.0 & 1.5 & 3.0 & 1.5 & 0.3 & 0.6 & 40.0 & $7.9 \pm 1.6^{\mathrm{d}}$ & $32.5 \pm 1.0$ \\
\hline 2 & 50.0 & 15.0 & 15.0 & 1.5 & 3.0 & 1.0 & 0.3 & 0.3 & 60.0 & $4.2 \pm 0.4$ & $32.2 \pm 1.3$ \\
\hline 3 & 80.0 & 10.0 & 15.0 & 1.5 & 1.5 & 1.0 & 0.6 & 0.6 & 60.0 & $6.2 \pm 0.3$ & $51.9 \pm 4.8$ \\
\hline 4 & 80.0 & 15.0 & 10.0 & 3.0 & 1.5 & 1.0 & 0.3 & 0.6 & 60.0 & $9.3 \pm 0.4$ & $50.2 \pm 3.1$ \\
\hline 5 & 50.0 & 10.0 & 10.0 & 3.0 & 3.0 & 1.5 & 0.3 & 0.6 & 60.0 & $2.6 \pm 0.6$ & $36.2 \pm 0.6$ \\
\hline 6 & 80.0 & 10.0 & 10.0 & 1.5 & 3.0 & 1.5 & 0.6 & 0.3 & 60.0 & $6.7 \pm 0.1$ & $50.4 \pm 1.5$ \\
\hline 7 & 50.0 & 10.0 & 10.0 & 1.5 & 1.5 & 1.0 & 0.3 & 0.3 & 40.0 & $5.9 \pm 0.3$ & $36.0 \pm 0.2$ \\
\hline 8 & 50.0 & 15.0 & 15.0 & 3.0 & 1.5 & 1.5 & 0.6 & 0.3 & 60.0 & $2.9 \pm 0.5$ & $33.2 \pm 1.2$ \\
\hline 9 & 50.0 & 10.0 & 15.0 & 3.0 & 3.0 & 1.0 & 0.6 & 0.6 & 40.0 & $5.3 \pm 0.3$ & $35.4 \pm 1.2$ \\
\hline 10 & 80.0 & 15.0 & 10.0 & 3.0 & 3.0 & 1.0 & 0.6 & 0.3 & 40.0 & $9.1 \pm 0.5$ & $36.3 \pm 0.6$ \\
\hline 11 & 50.0 & 15.0 & 10.0 & 1.5 & 1.5 & 1.5 & 0.6 & 0.6 & 40.0 & $10.0 \pm 0.6$ & $36.5 \pm 2.7$ \\
\hline 12 & 80.0 & 10.0 & 15.0 & 3.0 & 1.5 & 1.5 & 0.3 & 0.3 & 40.0 & $6.3 \pm 0.6$ & $38.3 \pm 0.7$ \\
\hline
\end{tabular}

${ }^{\mathrm{a}}$ The two dummy was not shown in Table 1.

bYE: yeast extract.

${ }^{\mathrm{c} C S L}$ : corn steep liquor.

${ }^{\mathrm{d} S t a n d a r d ~ e r r o r ~ w a s ~ c a l c u l a t e d ~ f r o m ~ t h r e e ~ i n d e p e n d e n t ~ s a m p l e s . ~}$

TABLE 2: Experiment design and results of the steepest ascent path.

\begin{tabular}{lccccc}
\hline Runs & Glucose $\left(\mathrm{g} \mathrm{L}^{-1}\right)$ & Yeast extract $\left(\mathrm{g} \mathrm{L}^{-1}\right)$ & $\mathrm{MgCO}_{3}\left(\mathrm{~g} \mathrm{~L}^{-1}\right)$ & $\mathrm{OD}_{660}$ & Succinic acid production $\left(\mathrm{g} \mathrm{L}^{-1}\right)$ \\
\hline 1 & 80 & 10 & 60 & $6.1 \pm 0.2^{\mathrm{a}}$ & $48.4 \pm 1.3$ \\
2 & 85 & 7 & 65 & $3.7 \pm 0.7$ & $41.7 \pm 2.6$ \\
3 & 90 & 4 & 70 & $0.6 \pm 0.0$ & $36.4 \pm 2.4$ \\
4 & 95 & 1 & 75 & $0.2 \pm 0.0$ & $22.1 \pm 5.3$ \\
5 & 100 & 0 & 80 & $0.1 \pm 0.0$ & $4.2 \pm 1.1$ \\
\hline
\end{tabular}

${ }^{\mathrm{a}}$ Standard error was calculated from three independent samples.

TABLE 3: The Box-Behnken design of RSM for the optimization of succinic acid production by A. succinogenes ATCC 55618.

\begin{tabular}{|c|c|c|c|c|c|}
\hline Run & Glucose $\left(\mathrm{g} \mathrm{L}^{-1}\right)$ & Yeast extract $\left(\mathrm{g} \mathrm{L}^{-1}\right)$ & $\mathrm{MgCO}_{3}\left(\mathrm{~g} \mathrm{~L}^{-1}\right)$ & $\mathrm{OD}_{660}$ & Succinic acid production $\left(\mathrm{g} \mathrm{L}^{-1}\right)$ \\
\hline 1 & $70(-1)^{\mathrm{a}}$ & $10(0)$ & $50(-1)$ & $6.0 \pm 0.7^{c}$ & $38.9 \pm 1.3$ \\
\hline 2 & $90(1)$ & $10(0)$ & $50(-1)$ & $5.5 \pm 0.8$ & $40.3 \pm 0.7$ \\
\hline 3 & $70(-1)$ & $10(0)$ & $70(1)$ & $0.6 \pm 0.1$ & $43.2 \pm 5.5$ \\
\hline 4 & $90(1)$ & $10(0)$ & $70(1)$ & $5.7 \pm 0.4$ & $45.8 \pm 0.9$ \\
\hline 5 & $70(-1)$ & $5(-1)$ & $60(0)$ & $1.3 \pm 0.6$ & $37.0 \pm 2.5$ \\
\hline 6 & $90(1)$ & $5(-1)$ & $60(0)$ & $1.0 \pm 0.8$ & $38.1 \pm 4.0$ \\
\hline 7 & $70(-1)$ & $15(1)$ & $60(0)$ & $8.0 \pm 0.2$ & $45.8 \pm 1.3$ \\
\hline 8 & $90(1)$ & $15(1)$ & $60(0)$ & $7.8 \pm 0.6$ & $50.9 \pm 0.7$ \\
\hline 9 & $80(0)$ & $5(-1)$ & $50(-1)$ & $0.8 \pm 0.6$ & $35.1 \pm 1.7$ \\
\hline 10 & $80(0)$ & $5(-1)$ & $70(1)$ & $0.5 \pm 0.1$ & $34.8 \pm 1.1$ \\
\hline 11 & $80(0)$ & $15(1)$ & $50(-1)$ & $8.3 \pm 0.2$ & $41.5 \pm 2.6$ \\
\hline 12 & $80(0)$ & $15(1)$ & $70(1)$ & $6.2 \pm 0.2$ & $50.7 \pm 0.8$ \\
\hline $13^{b}$ & $80(0)$ & $10(0)$ & $60(0)$ & $6.5 \pm 1.0$ & $49.6 \pm 1.0$ \\
\hline $14^{\mathrm{b}}$ & $80(0)$ & $10(0)$ & $60(0)$ & $5.8 \pm 0.1$ & $50.2 \pm 1.5$ \\
\hline $15^{\mathrm{b}}$ & $80(0)$ & $10(0)$ & $60(0)$ & $5.9 \pm 0.1$ & $49.0 \pm 3.5$ \\
\hline
\end{tabular}

${ }^{a}$ Real values of independent variables and the corresponding coded level.

${ }^{\mathrm{b}}$ Runs $13-15$ were three replications.

${ }^{c}$ For each trial, the dynamic profile of the succinic acid production was monitored. Multiple flasks were run at the same time, and three flasks were taken at each sampling point. Each data point was expressed by an average with an error bar (i.e., standard error from three independent samples). 
model was developed by the following second-order polynomial equation to fit data in RSM of BBD:

$$
\begin{array}{r}
Y=\beta_{0}+\sum \beta_{i} x_{i}+\sum \beta_{i i} x_{i}^{2}+\sum_{i=1}^{n} \beta_{i j} x_{i} x_{j}+\varepsilon \\
i \neq j ; i, j=1,2,3 \ldots,
\end{array}
$$

where $Y$ is the predicted response, $\beta_{0}$ is the offset term, $\beta_{i}$ is the linear effect, $\beta_{i i}$ is the quadratic effect, $\beta_{i j}$ is the interaction effect, and $\varepsilon$ is an experimental error. And $x_{i}$ and $x_{j}$ represent the independent variables (medium components) in the form of coded values as follows:

$$
x_{i}=\frac{X_{i}-X}{\Delta X_{i}} \quad i=1,2,3,
$$

where $x_{i}$ and $X_{i}$ are the dimensionless and the actual values of independent variable $i, X$ is the actual value of the independent variable $i$ at the central point, and $\Delta X_{i}$ is the step change of $X_{i}$ corresponding to a unit variation of the dimensionless value.

The model of response was expression in terms of code variables and without the statistically insignificant terms (different models are available in BBD of statistical software package Minitab 15, Minitab Inc., State College, PA 168013008, USA).

2.6. Data Analysis. Standardized Pareto charts, representing the estimated effects of parameters and parameter interactions on responses, permitted us to check the statistical significance of the PBD. The Student's $t$-test permitted to check the statistical significance of the regression coefficients. The analysis of variable (ANOVA) was performed on experimental data to evaluate the statistical significance of the model. The models of each response were expressed in terms of code/uncoded variables and without the statistically insignificant terms. A $p$ value less than $5 \%$ indicates that model terms are significant, while less than $1 \%$ indicates that model terms are highly significant. A $p$ value is a measure of how much evidence one has against the null hypothesis (the null hypothesis of the test read like this: $\mathrm{H} 0: \beta_{1}=\beta_{2}=$ $\cdots=\beta_{i}=0 ; \mathrm{H1}$ : at least one $\beta$ is not zero) and evidence against null hypothesis is more for smaller $p$ value. A $p$ value of 0.05 or less rejects the null hypothesis at the $5 \%$ level, that is, only $5 \%$ of the probability the supposed statistical model will fail to predict the response. The model adequacies were checked by the determination coefficients $\left(R^{2}\right)$, adjusted $R^{2}$, and predicted $R^{2}$. The determination coefficient $\left(R^{2}\right)$ is a measure of how well the regression equation fits the sample data. While $R^{2}$ can be made larger simply by adding more predictor variables to the model, an adjusted $R^{2}$ has been proposed. Adjusted $R^{2}$ is a modification of $R^{2}$ that adjusts for the number of explanatory terms in a model. A predicted $R^{2}$ is used to measure the amount of variation in new data (i.e., other levels among the tested maximal value and minimal value of the factor) explained by the model. It is calculated by systematically removing each observation from the data set, estimating the regression equation, and determining how well the model predicts the removed observation. Predicted $R^{2}$ is used in regression analysis to indicate how well the model predicts responses for new observations, whereas $R^{2}$ indicates how well the model fits the data. Predicted $R^{2}$ can prevent overfitting the model and can be more useful than adjusted $R^{2}$ for comparing models because it is calculated using observations not included in model estimation. Predicted $R^{2}$ larger values of predicted $R$ squared suggest models of greater predictive ability. The predicted $R^{2}$ and the adjusted $R^{2}$ should be within 0.20 of each other. Otherwise there may be a problem with either the data or the model. The "Minitab 15 (Minitab Inc., State College, PA 16801-3008, USA)" software was employed for the regression analysis and the graphical optimization, respectively.

2.7. Sampling and the Determination of Succinic Acid Production. For sampling, three flasks were taken each time, and cell growth was monitored by measuring the optical density at $660 \mathrm{~nm}\left(\mathrm{OD}_{660}\right)$. At an $\mathrm{OD}_{660}$ of 1.0 , A. succinogenes ATCC 55618 has a concentration of $0.626 \mathrm{~g}$ dry cell weight $(\mathrm{DCW}) \mathrm{l}^{-1}$. For succinic acid determination, $1 \mathrm{~mL}$ of methanol and $1 \mathrm{~mL}$ of acetonitrile were added to $1 \mathrm{~mL}$ of fermentation broth to remove proteins, and the sample was kept at $4^{\circ} \mathrm{C}$ overnight. After centrifugation at $11,000 \mathrm{rpm}$ for $30 \mathrm{~min}$, the supernatants were diluted and filtrated through a $0.22-\mu \mathrm{m}$ filter and analyzed by high-performance liquid chromatography (HPLC, Waters) using an Agela Venusil ASB C18 column. The optimized mobile phase was $50 \mathrm{mM}$ $\mathrm{KH}_{2} \mathrm{PO}_{4}$ water solution, with the $\mathrm{pH}$ adjusted to 3.5 by $\mathrm{H}_{3} \mathrm{PO}_{4}$. The column oven temperature was maintained at $40^{\circ} \mathrm{C}$, and the flow rate was $1 \mathrm{~mL} \mathrm{~min}{ }^{-1}$. The detection wave was fixed at $210 \mathrm{~nm}$.

\section{Results and Discussion}

3.1. Plackett-Burman Design (PBD). The methodology of Plackett-Burman design (PBD) is a powerful and useful tool in rapidly searching key factors from a multivariable system. PBD does not determine the exact quantity, but it can provide some important information about each factor by relatively few experiments [19]. As shown in Table 1, PBD for 12 trials with two levels of concentrations was undertaken to evaluate the significances of nine medium components. In order to determine the influence of the most important parameters, a standardized Pareto chart (Figure 1) was employed. Analysis of the measured response variables enabled to obtain standardized Pareto charts and response surface plots. A standardized Pareto chart consists of bars with a length proportional to the absolute value of the estimated effects, divided by the standard error. The bars are displayed in order of the size of the effects, with the largest effects on top. The chart includes a vertical line at the critical $t$-value for an alpha. Some investigations find that the confidence levels greater than $80 \%(p<0.2)$ are acceptable [21]. In this study, the chart includes a vertical line at the critical $t$-value for $\alpha$ of 0.20 . Effects for which the bars are smaller than the critical $t$-value are considered as not 


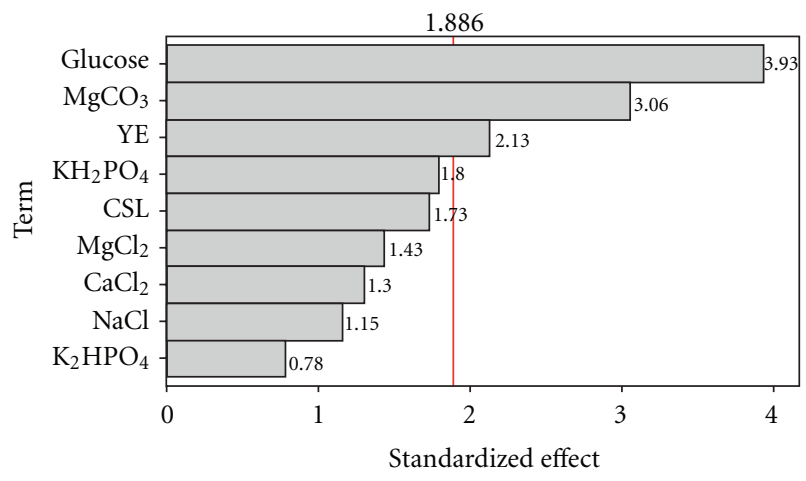

Figure 1: Pareto chart of standardized effects on the succinic acid production. The chart includes a vertical line (i.e., standardized effect $=1.886)$ at the critical $t$-value for $\alpha$ of 0.20 . The bars are displayed in order of the size of the effects, and the standardized effect of each term was shown on the top of its corresponding bar.

significant and not affecting the response variables. Effects may be positive or negative.

As shown in Figure 1, for the succinic acid production, the variables glucose, yeast extract, and $\mathrm{MgCO}_{3}$ had a confidence level above $80 \%$. Hence, these were considered to be significant for the succinic acid biosynthesis.

Analyzed by Minitab, a first-order model, was fitted to the results obtained from the twelve experiments as the equation:

$$
\begin{aligned}
Y\left(\mathrm{~g} \mathrm{~L}^{-1}\right)= & 39.09+4.18 C_{\text {glucose }}-2.28 C_{\mathrm{YE}}-1.84 C_{\mathrm{CSL}} \\
& -0.83 C_{\mathrm{K}_{2} \mathrm{HPO}_{4}}-1.93 C_{\mathrm{KH}_{2} \mathrm{PO}_{4}}-1.24 C_{\mathrm{NaCl}} \\
& +1.53 C_{\mathrm{MgCl}_{2}}+1.36 C_{\mathrm{CaCl}_{2}}+3.26 C_{\mathrm{MgCO}_{3}} .
\end{aligned}
$$

where $Y$ is the succinic acid production, and $C_{\mathrm{Glucose}}, C_{\mathrm{YE}}$, $C_{\mathrm{CSL}}, C_{\mathrm{K}_{2} \mathrm{HPO}_{4}}, C_{\mathrm{KH}_{2} \mathrm{PO}_{4}}, C_{\mathrm{NaCl}}, C_{\mathrm{MgCl}_{2}}, C_{\mathrm{CaCl}_{2}}$, and $C_{\mathrm{MgCO}_{3}}$ are the value of glucose, YE, CSL, $\mathrm{K}_{2} \mathrm{HPO}_{4}, \mathrm{KH}_{2} \mathrm{PO}_{4}, \mathrm{NaCl}$, $\mathrm{MgCl}_{2}, \mathrm{CaCl}_{2}$, and $\mathrm{MgCO}_{3}$, respectively. The goodness of the regression was checked by the coefficient of determination $R^{2}$ whose value $\left(R^{2}=95.39 \%\right)$ indicates that only $4.61 \%$ of the total variation could not be explained by the model, and it was reasonable to use the regression model to analyze the trend in the response. And then, glucose, yeast extract, and $\mathrm{MgCO}_{3}$ were selected for further optimization to obtain a maximum response. According to the coefficients of the glucose (4.18), yeast extract $(-2.28)$ and $\mathrm{MgCO}_{3}(3.26)$, the positive coefficients indicated that the high level of glucose and $\mathrm{MgCO}_{3}$ concentration in $\mathrm{PBD}$ was benefit for the succinic acid production. On the contrary, the negative coefficient indicated that the low level of yeast extract concentration was helpful for the succinic acid accumulation. A maximum succinic acid production of $51.9 \mathrm{~g} \mathrm{~L}^{-1}$ was obtained with $80.0 \mathrm{~g} \mathrm{~L}^{-1}$ of glucose, $60.0 \mathrm{~g} \mathrm{~L}^{-1}$ of $\mathrm{MgCO}_{3}$, and $10.0 \mathrm{~g} \mathrm{~L}^{-1}$ of yeast extract. The corresponding productivity and specific productivity were $1.1 \mathrm{~g} \mathrm{~L}^{-1} \mathrm{~h}^{-1}$ and $13.4 \mathrm{~g}$ succinic acid $\mathrm{g}^{-1}$ DCW. However, the $\mathrm{OD}_{660}$ of 6.2 obtained with this medium was not the highest among the 12 conditions.
According to the metabolic pathway of A. succinogenes, succinic acid was an end-product from the substrate of glucose, which implied that succinic acid formation was decided by the supplement of glucose directly [22]. The yield of succinic acid against glucose was improved by the increase of initial glucose concentration, and it would reach the peak value when the initial glucose concentration was $70.0 \mathrm{~g} \mathrm{~L}^{-1}$ [23].

The culture $\mathrm{pH}$ value is one of the key factors in the production of succinic acid [24]. $\mathrm{MgCO}_{3}$ was used as a neutralizing agent and added to the fermentation broth to adjust culture $\mathrm{pH}$. Before optimization, the $\mathrm{pH}$ value decreased from 7.5 to 5.7 during the fermentation. Compared with the $\mathrm{pH}$ value of basic medium, the initial $\mathrm{pH}$ increased up to 8.0 and was followed by slow decline after the optimization. So after $\mathrm{MgCO}_{3}$ was elevated, the extent of system buffering was improved. The final $\mathrm{pH}$ value of optimal medium with an initial $\mathrm{pH}$ of 7.5 was more close to neutral (about 6.5) during the fermentation, and neutral environment was helpful to accumulate succinic acid. In our previous results, the highest succinic acid production of $48.2 \mathrm{~g} \mathrm{~L}^{-1}$ was obtained at a culture $\mathrm{pH}$ of 7.5 [25]. The pattern of succinic acid production at a culture $\mathrm{pH}$ of 7.0 was similar with that obtained at 7.5. When the initial culture $\mathrm{pH}$ was adjusted to 6.5 or 8.0 , a significant decrease of succinic acid production was observed. So, the effect of medium optimization $\mathrm{MgCO}_{3}$ may be partly from the influence of the $\mathrm{pH}$.

On the other hand, sufficient $\mathrm{CO}_{2}$ supplement in the fermentation broth could strongly influence the metabolic flux of carbon and the activities of phosphoenolpyruvate (PEP) carboxykinase, which were the important committed steps for the biosynthesis of succinic acid [24, 26]; therefore, sufficient $\mathrm{CO}_{2}$ is another key factor influencing succinic acid accumulation. However, in our previous work, there was no significant effect of $\mathrm{CO}_{2}$ partial pressure on the production of succinic acid when gaseous $\mathrm{CO}_{2}$ was used as the sole $\mathrm{CO}_{2}$ donor [27]. As an important $\mathrm{CO}_{2}$ donor in the A. succinogenes fermentation, $\mathrm{MgCO}_{3}$ could react with organic acids in fermentation broth and caused an increase in the dissolved concentrations of $\mathrm{HCO}_{3}{ }^{-}, \mathrm{CO}_{3}{ }^{2-}$, and $\mathrm{CO}_{2}$. When gaseous $\mathrm{CO}_{2}$ was used with $\mathrm{MgCO}_{3}$, higher amount of $\mathrm{MgCO}_{3}$ was more effective on promoting the succinic acid synthesis. And the maximum succinic acid production of $61.92 \mathrm{~g} \mathrm{~L}^{-1}$ was obtained at $159.22 \mathrm{mM}$ dissolved $\mathrm{CO}_{2}$ concentration, which was supplied by $40 \mathrm{~g} \mathrm{~L}^{-1}$ $\mathrm{MgCO}_{3}$ with $100 \% \mathrm{CO}_{2}$ gas. This means that the dissolved $\mathrm{CO}_{2}$ concentration was another factor affecting succinic acid synthesis. And during the fermentation process, insoluble $\mathrm{MgCO}_{3}$ caused turbid broth, which made the cells spread uniformly in the broth. This effectively avoids the cell flocculation. All these properties make $\mathrm{MgCO}_{3}$ to be one of the key factors significantly improved the succinic acid production.

At last, yeast extract was also screened to be a key factor because it affected cell growth directly as the nutrient. It contains many trace substances, such as folic acid, pantothenic acid, biotin, and vitamin $\mathrm{B}_{1}, \mathrm{~B}_{2}, \mathrm{~B}_{6}$, and $\mathrm{B}_{12}$. This may be the important reason why many kinds of vitamins could 
be omitted meanwhile the succinic acid could efficiently be accumulated in this work.

To conclude, the variables of glucose, $\mathrm{MgCO}_{3}$, and yeast extract had a confidence level above $80 \%$ and hence were considered to significantly influence the succinic acid production. The optimal concentrations of these three key components needed to be further studied as follows.

3.2. Steepest Ascent (SA). Based on the results above, glucose, yeast extract, and $\mathrm{MgCO}_{3}$ were the three key factors, and the high level of glucose (i.e., $80.0 \mathrm{~g} \mathrm{~L}^{-1}$ ) and $\mathrm{MgCO}_{3}$ (i.e., $60.0 \mathrm{~g} \mathrm{~L}^{-1}$ ), while the low level of yeast extract (i.e., $10.0 \mathrm{~g} \mathrm{~L}^{-1}$ ) was benefit for the succinic acid production of $A$. succinogenes ATCC 55618. Thus, the path of SA was moved along the path in which glucose and $\mathrm{MgCO}_{3}$ increased, while yeast extract decreased (Table 2). The highest succinic acid production of $48.4 \pm 1.3 \mathrm{~g} \mathrm{~L}^{-1}$ and $\mathrm{OD}_{660}$ of 6.1 was observed under the point of levels, namely, $80.0 \mathrm{~g} \mathrm{~L}^{-1}$ of glucose, $10.0 \mathrm{~g} \mathrm{~L}^{-1}$ of yeast extract, and $60.0 \mathrm{~g} \mathrm{~L}^{-1}$ of $\mathrm{MgCO}_{3}$. The corresponding productivity and specific productivity were $1.0 \mathrm{~g} \mathrm{~L}^{-1} \mathrm{~h}^{-1}$ and $12.4 \mathrm{~g}$ succinic acid $\mathrm{g}^{-1}$ DCW. This result suggested that the point was near the optimal point and was chosen for further optimization.

As shown in Table 2, the succinic acid production did not further increase with the increase concentrations of glucose and $\mathrm{MgCO}_{3}$ and the decrease concentration of yeast extract. For glucose, although A. succinogenes could tolerate glucose concentration as high as $150.0 \mathrm{~g} \mathrm{~L}^{-1}$, the yield of succinic acid would decrease when glucose concentration exceeds $70.0 \mathrm{~g} \mathrm{~L}^{-1}[9,23]$. So when the concentration of glucose increased from 80.0 to $100.0 \mathrm{~g} \mathrm{~L}^{-1}$, the concentrations of succinic acid could not be further improved. For $\mathrm{MgCO}_{3}$, the culture $\mathrm{pH}$ of fermentation broth was increased with the increase of $\mathrm{MgCO}_{3}$ concentration (data not shown), which may make the cells more difficult to adapt. Therefore, the succinic acid production was not enhanced. For yeast extract, it was observed that the absence of yeast extract led to almost no succinic acid accumulation, which indicated that this component was the basic nutrient for the cell growth.

To conclude, the highest succinic acid production was obtained under the condition of $80.0 \mathrm{~g} \mathrm{~L}^{-1}$ of glucose, $10.0 \mathrm{~g} \mathrm{~L}^{-1}$ of yeast extract, and $60.0 \mathrm{~g} \mathrm{~L}^{-1}$ of $\mathrm{MgCO}_{3}$, which suggested that this point was near the optimal point.

3.3. Box-Behnken Design (BBD). Based on the information above, taking the point $\left(80.0 \mathrm{~g} \mathrm{~L}^{-1}\right.$ of glucose, $10.0 \mathrm{~g} \mathrm{~L}^{-1}$ of yeast extract and $60.0 \mathrm{~g} \mathrm{~L}^{-1}$ of $\mathrm{MgCO}_{3}$ ) as the central level of $\mathrm{BBD}$, then the three-factors, three-level BBD was employed (Table 3).

Table 4 shows the analysis of variance (ANOVA) for the $\mathrm{BBD}$. The $p$ values $\leq 0.05$ indicate that the model terms are significant. The Lack of fit (LOF) is the variation of the data around the fitted model. LOF is a model fit test that is used to check how well a model fits the data and help to remove insignificant terms from the model. A $p$-value of LOF 0.614 indicted that the model fits the response well.

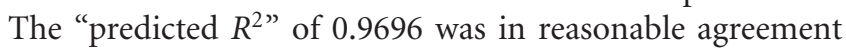
with the "adjusted $R^{2}$ " of 0.9911 , and it might be also
TABLE 4: Analysis of variance (ANOVA) for regression model.

\begin{tabular}{lccccc}
\hline Source & $\mathrm{SS}^{\mathrm{a}}$ & $\mathrm{DF}$ & $\mathrm{MS}$ & $F$ & $p$ \\
\hline Model & 481.38 & 9 & 53.49 & 174.13 & $<0.001$ \\
Linear & 298.58 & 3 & 99.53 & 324.01 & $<0.001$ \\
Quadratic & 155.85 & 3 & 51.95 & 169.12 & $<0.001$ \\
Interactions & 26.95 & 3 & 8.98 & 29.24 & 0.001 \\
Residual & 1.54 & 5 & 0.31 & & \\
Lack of fit & 0.82 & 3 & 0.27 & 0.75 & 0.614 \\
Pure error & 0.72 & 2 & 0.36 & & \\
Total SS & 482.91 & 14 & & \\
\hline \multicolumn{5}{c}{$R^{2}=0.9968, R_{\mathrm{adj}}^{2}=0.9911, R_{\text {pred }}^{2}=0.9696}$. \\
\hline
\end{tabular}

${ }^{a}$ SS: sum of squares; DF: degrees of freedom; MS: mean square; $R^{2}$ : determination coefficient; adj $R^{2}$ : adjusted $R^{2}$; pred $R^{2}$ : predicted $R^{2}$.

said that the model determination coefficient ( $R^{2}$ of 0.9968$)$ was reasonable agreement with the experimental results, indicating that $99.68 \%$ of the variability could be revealed by the model.

The polynomial model for the succinic acid production was expressed by (8) (in coded value) and (9) (in uncoded value) (Table 5) consider the following:

$$
\begin{aligned}
Y= & 49.563+1.274 A+5.495 B+2.346 C+1.008 A B \\
& +0.310 A C+2.373 B C-2.562 A^{2}-4.084 B^{2}-4.972 C^{2}
\end{aligned}
$$

$$
\begin{aligned}
Y= & -285.728+3.842 C_{\mathrm{Glucose}}-0.092 C_{\mathrm{YE}}+5.482 C_{\mathrm{MgCO}_{3}} \\
& +0.020 C_{\mathrm{Glucose}} C_{\mathrm{YE}}+0.0031 C_{\mathrm{Glucose}} C_{\mathrm{MgCO}_{3}} \\
& +0.047 C_{\mathrm{YE}} C_{\mathrm{MgCO}_{3}}-0.026 C_{\mathrm{Glucose}^{2}} \\
& -0.163 C_{\mathrm{YE}}^{2}-0.050 C_{\mathrm{MgCO}_{3}}^{2}
\end{aligned}
$$

The model reveals that glucose concentration $(A)$, yeast extract concentration $(B)$, and $\mathrm{MgCO}_{3}$ concentration $(C)$ had a significant effect $(p<0.0001)$ on the succinic acid production $(Y)$. Positive coefficient of $A, B$, and $C$ indicated a linear effect to increase. However, quadratic term $A^{2}, B^{2}$, and $C^{2}$ had the negative effect. The graphs (Figure 2) depict the changes in the parameter modeled as the two factors move along those levels, while the other factor held constant at the central point. According to (9), the highest succinic acid production of $52.3 \mathrm{~g} \mathrm{~L}^{-1}$ was obtained at $14.0 \mathrm{~g} \mathrm{~L}^{-1}$ of yeast extract and $64.3 \mathrm{~g} \mathrm{~L}^{-1}$ of $\mathrm{MgCO}_{3}$, while glucose concentration was held at $80.0 \mathrm{~g} \mathrm{~L}^{-1}$; the maximal succinic acid production of $50.0 \mathrm{~g} \mathrm{~L}^{-1}$ could be observed at $82.6 \mathrm{~g} \mathrm{~L}^{-1}$ of glucose and $62.4 \mathrm{~g} \mathrm{~L}^{-1}$ of $\mathrm{MgCO}_{3}$, while holding $10.0 \mathrm{~g} \mathrm{~L}^{-1}$ of yeast extract; under the conditions of $83.9 \mathrm{~g} \mathrm{~L}^{-1}$ of glucose, $13.6 \mathrm{~g} \mathrm{~L}^{-1}$ of yeast extract and $60.0 \mathrm{~g} \mathrm{~L}^{-1}$ of $\mathrm{MgCO}_{3}$ (the factor held constant), the succinic acid production could reach its peak value of $51.8 \mathrm{~g} \mathrm{~L}^{-1}$. According to (8) and (9), it was predicted that a maximum succinic acid production of $53.0 \mathrm{~g} \mathrm{~L}^{-1}$ was appeared at $84.6 \mathrm{~g} \mathrm{~L}^{-1}$ of glucose, $14.5 \mathrm{~g} \mathrm{~L}^{-1}$ of yeast extract, and $64.7 \mathrm{~g} \mathrm{~L}^{-1}$ of $\mathrm{MgCO}_{3}$. 


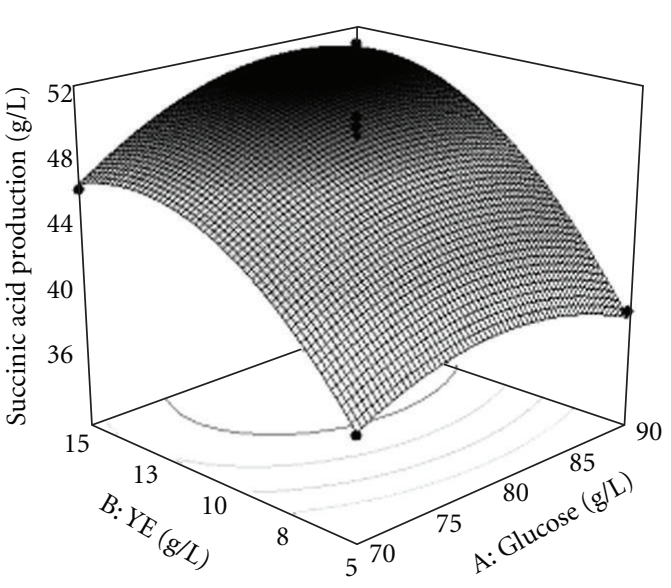

(a)

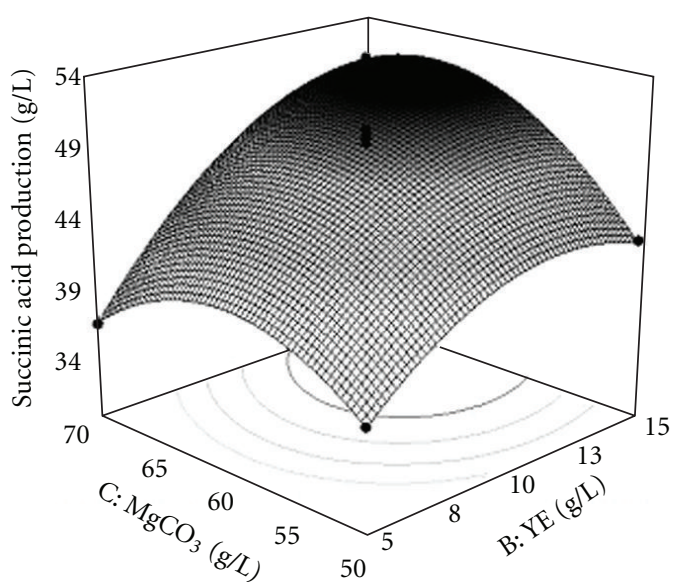

(b)

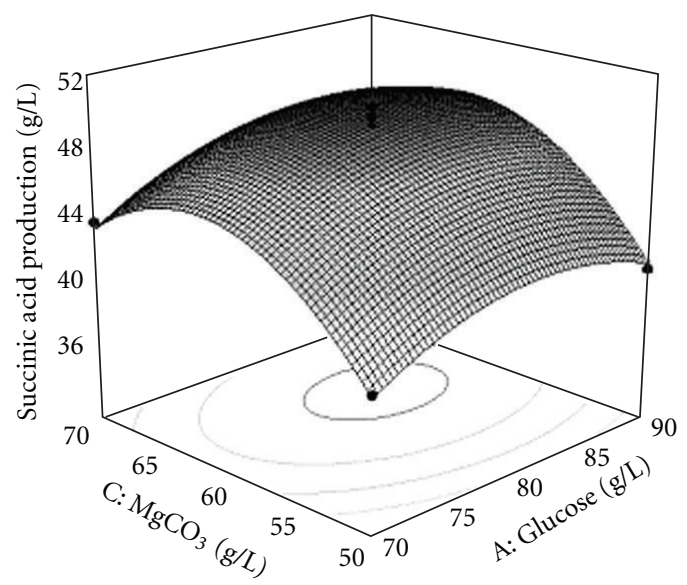

(c)

FIGURE 2: Response surface curve for the succinic acid production by Actinobacillus succinogenes ATCC 55618 showing the combination effects of (a) glucose and yeast extract, (b) yeast extract and $\mathrm{MgCO}_{3}$, and (c) glucose and $\mathrm{MgCO}_{3}$. Other factors are constant at zero levels.

TABLE 5: Regression coefficients and their significance for response surface model.

\begin{tabular}{lcccc}
\hline Term & Coefficient & Standard error & $T(C / S)$ & $p$ \\
\hline Intercept & 49.563 & 0.32 & 154.89 & $<0.001^{\mathrm{a}}$ \\
$A-$ Glucose & 1.274 & 0.20 & 6.50 & $0.001^{\mathrm{a}}$ \\
$B$-Yeast extract & 5.495 & 0.20 & 28.04 & $<0.001^{\mathrm{a}}$ \\
$C-\mathrm{MgCO}_{3}$ & 2.346 & 0.20 & 11.97 & $<0.001^{\mathrm{a}}$ \\
$A B$ & 1.008 & 0.29 & 3.64 & $0.015^{\mathrm{b}}$ \\
$A C$ & 0.310 & 0.29 & 1.10 & 0.321 \\
$B C$ & 2.373 & 0.29 & 8.56 & $<0.001^{\mathrm{a}}$ \\
$A^{2}$ & -2.562 & 0.28 & -8.88 & $<0.001^{\mathrm{a}}$ \\
$B^{2}$ & -4.084 & 0.28 & -14.16 & $<0.001^{\mathrm{a}}$ \\
$C^{2}$ & -4.972 & 0.28 & -17.24 & $<0.001^{\mathrm{a}}$ \\
\hline
\end{tabular}

a Significant at $1 \%$ level.

${ }^{\mathrm{b}}$ Significant at $5 \%$ level.

In a word, the best level combination of the three key factors (i.e., glucose, yeast extract, and $\mathrm{MgCO}_{3}$ ) was predicted by the polynomial model from BBD. Then the reliability of the model and the accuracy of the prediction should be checked by verification experiment.
3.4. Model Verification. The availability of the regression model of the succinic acid production using the calculated optimal medium compositions, namely, $84.6 \mathrm{~g} \mathrm{~L}^{-1}$ glucose, $14.5 \mathrm{~g} \mathrm{~L}^{-1}$ yeast extract, and $64.7 \mathrm{~g} \mathrm{~L}^{-1} \mathrm{MgCO}_{3}$, was validated with triplicate experiments. The mean maximal value of succinic acid production was $52.7 \pm 0.8 \mathrm{~g} \mathrm{~L}^{-1}$, which agreed with the predicted value $\left(53.0 \mathrm{~g} \mathrm{~L}^{-1}\right)$ well. As a result, the model was considered to be accurate and reliable for predicting the succinic acid production by $A$. succinogenes. Theoretically, $1.71 \mathrm{~mol}$ succinate can be produced per mol glucose (plus $\mathrm{CO}_{2}$ ), based on the available electrons (i.e., 24 electrons in glucose divided by 14 electrons in succinate $=1.71)$. In this work, compared with that of basic medium $\left(0.45 \mathrm{~mol} \mathrm{~mol}^{-1}\right.$ glucose), the yield of succinic acid against glucose was enhanced by $111.1 \%$ in optimized medium $\left(0.95 \mathrm{~mol} \mathrm{~mol}^{-1}\right.$ glucose). However, there is a certain gap between the yield and the theoretical value. This may be because there are some factors other than the medium, which affect the yield of succinic acid but are not investigated in this study.

Other authors have reported that the succinic acid production reached $84 \mathrm{gL}^{-1}$ in the fermentation of Actinobacillus succinogenes NJ113, in which the medium was with 
similar components to the basic medium in this work, and the corresponding yield of succinic acid was $1.20 \mathrm{~mol} \mathrm{~mol}^{-1}$ glucose [28]. Since NJ113 is the strain screened by Jiang et al, this strain may have greater ability to synthesize succinic acid.

To conclude, the best level combination of the three key factors (i.e., $84.6 \mathrm{~g} \mathrm{~L}^{-1}$ glucose, $14.5 \mathrm{~g} \mathrm{~L}^{-1}$ yeast extract, and $64.7 \mathrm{~g} \mathrm{~L}^{-1} \mathrm{MgCO}_{3}$ ) was obtained by using the statistical experimental design. The succinic acid production reached its peak values of $52.7 \pm 0.8 \mathrm{~g} \mathrm{~L}^{-1}$ under the optimal medium compositions, which agreed with the predicted value $\left(53.0 \mathrm{~g} \mathrm{~L}^{-1}\right)$ well and was $67.3 \%$ higher than that obtained with the basic medium (i.e., $31.5 \pm 2.3 \mathrm{~g} \mathrm{~L}^{-1}$ ).

\section{Conclusion}

In this study, a highly efficient optimization method by combining Plackett-Burman design, steepest ascent, and BoxBehnken design was developed. This method was demonstrated to be effective in selecting the significant factors and enhancing succinic acid production in A. succinogenes ATCC 55618 fermentation. Glucose, yeast extract, and $\mathrm{MgCO}_{3}$ were screened to be key factors for the succinic acid production. A maximal succinic acid production of $52.7 \pm 0.8 \mathrm{~g} \mathrm{~L}^{-1}$ was obtained with $84.6 \mathrm{~g} \mathrm{~L}^{-1}$ glucose, $14.5 \mathrm{~g} \mathrm{~L}^{-1}$ yeast extract, and $64.7 \mathrm{~g} \mathrm{~L}^{-1} \mathrm{MgCO}_{3}$. This result agreed with the predicted value well and was $67.3 \%$ higher than that obtained with the basic medium.

\section{Author's Contribution}

L.-W. Zhu and C.-C. Wang are equally contributed to this work.

\section{Acknowledgments}

Financial supports from the National Natural Science Foundation of China (NSFC, Project nos. 20976038 and 21176059), the Key Project of Chinese Ministry of Education (Project No. 210132), Hubei Provincial Natural Science Foundation for Innovative Research Team (Project No. 2008CDA002), Hubei Provincial Natural Science Foundation for Agriculture, Scientific Research Key Project of Hubei Provincial Department of Education (Project No. Z20101401), Discipline Leader Project of Wuhan Municipality (Project No. 200951830553), Key Technology R\&D Program of Wuhan Municipality (Project No. 2011208222802), the Open Project Programs for the Key Laboratory of Fermentation Engineering (Ministry of Education), the National Key Laboratory of Biochemical Engineering (Project No. 2010KF-06), and the State Key Laboratory of Bioreactor Engineering are gratefully acknowledged. YJ Tang also thanks the Chutian Scholar Program (Hubei Provincial Department of Education, China) (2006) and Program for New Century Excellent Talents in University (NCET-11-0961).

\section{References}

[1] H. Song and S. Y. Lee, "Production of succinic acid by bacterial fermentation," Enzyme and Microbial Technology, vol. 39, no. 3, pp. 352-361, 2006.
[2] T. Werpy and G. Petersen, "Top value added chemicals from biomass," Washington, DC, USA, US Department of Energy, 2004, http://wwwl.eere.energy.gov/biomass/pdfs/35523.pdf.

[3] D. Wilke, "Chemicals from biotechnology: molecular plant genetics will challenge the chemical and the fermentation industry," Applied Microbiology and Biotechnology, vol. 52, no. 2, pp. 135-145, 1999.

[4] I. Bechthold, K. Bretz, S. Kabasci, R. Kopitzky, and A. Springer, "Succinic acid: a new platform chemical for biobased polymers from renewable resources," Chemical Engineering and Technology, vol. 31, no. 5, pp. 647-654, 2008.

[5] T. Willke and K. D. Vorlop, "Industrial bioconversion of renewable resources as an alternative to conventional chemistry," Applied Microbiology and Biotechnology, vol. 66, no. 2, pp. 131-142, 2004.

[6] M. V. Guettler, D. Rumler, and M. K. Jain, “Actinobacillus succinogenes sp. nov., a novel succinic-acid-producing strain from the bovine 1umen," International Journal of Systematic Bacteriology, vol. 49, no. 1, pp. 207-216, 1999.

[7] K. Jantama, M. J. Haupt, S. A. Svoronos et al., "Combining metabolic engineering and metabolic evolution to develop nonrecombinant strains of Escherichia coli $\mathrm{C}$ that produce succinate and malate," Biotechnology and Bioengineering, vol. 99, no. 5, pp. 1140-1153, 2008.

[8] M. V. Guettler, M. K. Jain, and D. Rumler, "Method for making succinic acid, bacterial variants for use in the process, and methods for obtaining variants," US patent 5573931, 1996.

[9] M. V. Guettler, M. K. Jain, and B. K. Soni, "Process for making succinic acid, microorganisms for use in the process and methods of obtaining the microorganisms," US patent 5504004, 1996.

[10] M. V. Guettler, M. K. Jain, and B. K. Soni, "Process for making succinic acid, microorganisms for use in the process and methods of obtaining the microorganisms," US patent 5723322, 1998.

[11] C. Du, S. K. C. Lin, A. Koutinas, R. Wang, and C. Webb, "Succinic acid production from wheat using a biorefining strategy," Applied Microbiology and Biotechnology, vol. 76, no. 6, pp. 1263-1270, 2007.

[12] C. Du, S. K. C. Lin, A. Koutinas, R. Wang, P. Dorado, and C. Webb, "A wheat biorefining strategy based on solid-state fermentation for fermentative production of succinic acid," Bioresource Technology, vol. 99, no. 17, pp. 8310-8315, 2008.

[13] R. I. Corona-González, A. Bories, V. González-Álvarez, and C. Pelayo-Ortiz, "Kinetic study of succinic acid production by Actinobacillus succinogenes ZT-130," Process Biochemistry, vol. 43, no. 10, pp. 1047-1053, 2008.

[14] R. S. Liu and Y. J. Tang, "Tuber melanosporum fermentation medium optimization by Plackett-Burman design coupled with Draper-Lin small composite design and desirability function," Bioresource Technology, vol. 101, no. 9, pp. 31393146, 2010.

[15] R. H. Myers, "Response surface methodology—current status and future directions," Journal of Quality Technology, vol. 31, no. 1, pp. 30-44, 1999.

[16] V. Deepak, K. Kalishwaralal, S. Ramkumarpandian, S. V. Babu, S. R. Senthilkumar, and G. Sangiliyandi, "Optimization of media composition for nattokinase production by Bacillus subtilis using response surface methodology," Bioresource Technology, vol. 99, no. 17, pp. 8170-8174, 2008.

[17] J. Ren, W. T. Lin, Y. J. Shen, J. F. Wang, X. C. Luo, and M. Q. Xie, "Optimization of fermentation media for nitrite oxidizing bacteria using sequential statistical design," Bioresource Technology, vol. 99, no. 17, pp. 7923-7927, 2008. 
[18] X. Li, J. Ouyang, Y. Xu et al., "Optimization of culture conditions for production of yeast biomass using bamboo wastewater by response surface methodology," Bioresource Technology, vol. 100, no. 14, pp. 3613-3617, 2009.

[19] R. L. Plackett and J. P. Burman, "The design of optimum multifactorial experiments," Biometrika, vol. 33, pp. 305-325, 1946.

[20] R. Gheshlaghi, J. M. Scharer, M. Moo-Young, and P. L. Douglas, "Medium optimization for hen egg white lysozyme production by recombinant Aspergillus niger using statistical methods," Biotechnology and Bioengineering, vol. 90, no. 6, pp. 754-760, 2005.

[21] R. A. Stowe and R. P. Mayer, "Efficient screening of process variables." Industrial and Engineering Chemistry, vol. 58, pp. 36-40, 1966.

[22] J. B. McKinlay, J. G. Zeikus, and C. Vieille, "Insights into Actinobacillus succinogenes fermentative metabolism in a chemically defined growth medium," Applied and Environmental Microbiology, vol. 71, no. 11, pp. 6651-6656, 2005.

[23] S. K. C. Lin, C. Du, A. Koutinas, R. Wang, and C. Webb, "Substrate and product inhibition kinetics in succinic acid production by Actinobacillus succinogenes," Biochemical Engineering Journal, vol. 41, no. 2, pp. 128-135, 2008.

[24] N. S. Samuelov, R. Lamed, S. Lowe, and J. G. Zeikus, "Influence of $\mathrm{CO}_{2}-\mathrm{HCO}_{3}$ - levels and $\mathrm{pH}$ on growth, succinate production, and enzyme activities of Anaerobiospirillum succiniciproducens," Applied and Environmental Microbiology, vol. 57, no. 10, pp. 3013-3019, 1991.

[25] C. C. Wang, L. W. Zhu, H. M. Li, and Y. J. Tang, "Performance analyses of a neutralizing agent combination strategy for the production of succinic acid by Actinobacillus succinogenes ATCC 55618," Bioprocess and Biosystems Engineering, vol. 35, no. 4, pp. 659-664, 2012.

[26] J. B. McKinlay and C. Vieille, " ${ }^{13} \mathrm{C}-$ metabolic flux analysis of Actinobacillus succinogenes fermentative metabolism at different $\mathrm{NaHCO}_{3}$ and $\mathrm{H}_{2}$ concentrations," Metabolic Engineering, vol. 10, no. 1, pp. 55-68, 2008.

[27] W. Zou, L. W. Zhu, H. M. Li, and Y. J. Tang, "Significance of $\mathrm{CO}_{2}$ donor on the production of succinic acid by Actinobacillus succinogenes ATCC 55618," Microbial Cell Factories, vol. 10, article 87, 2011.

[28] M. Jiang, L. Su, K. Q. Chen, T. Cai, and Q. N. Wang, "Optimization of the culture condition for the production by anaerobic fermentation of Actinobacillus succinogenes NJ113," Food and Fermentation Industries, vol. 33, pp. 1-5, 2007 (Chinese). 

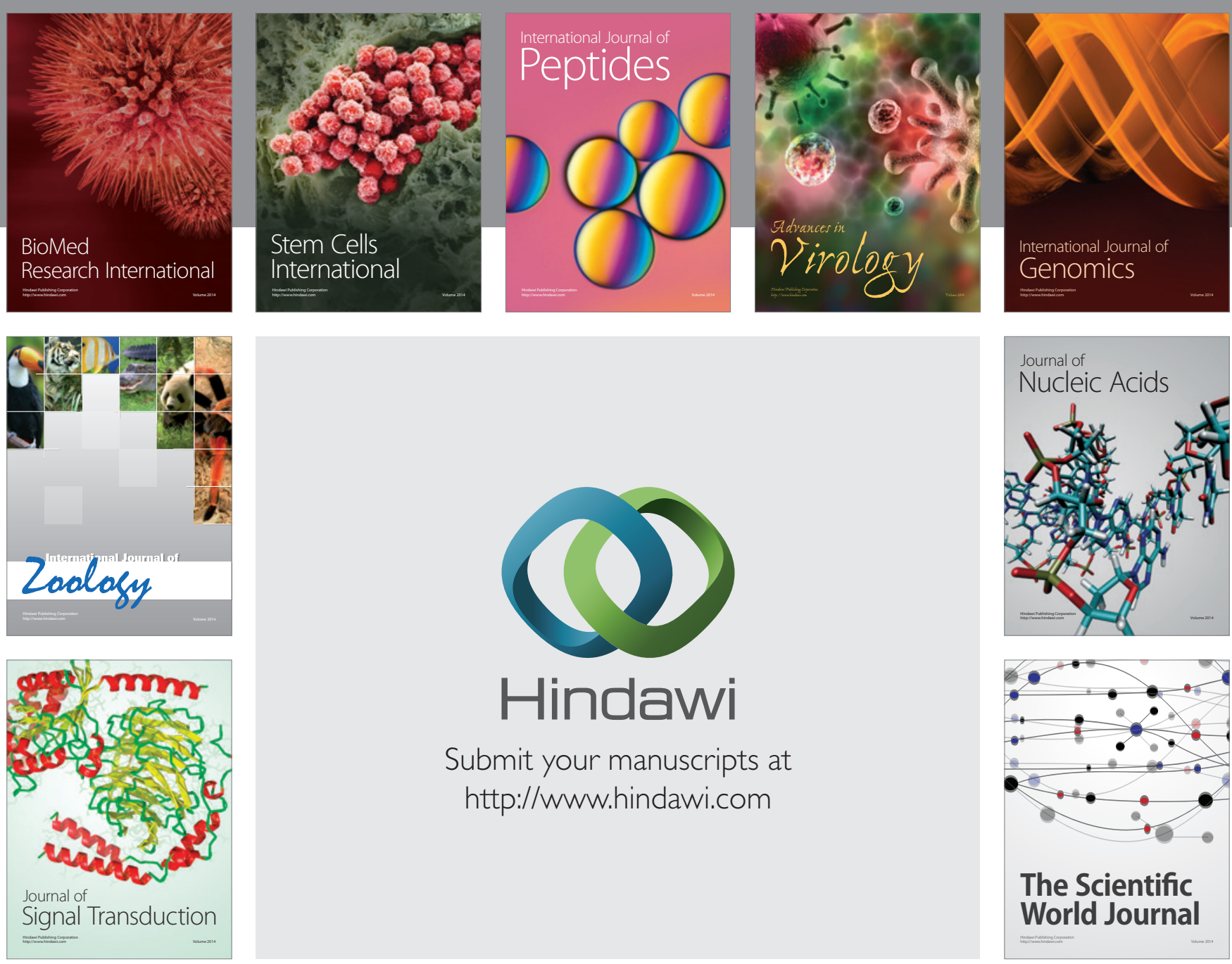

Submit your manuscripts at

http://www.hindawi.com
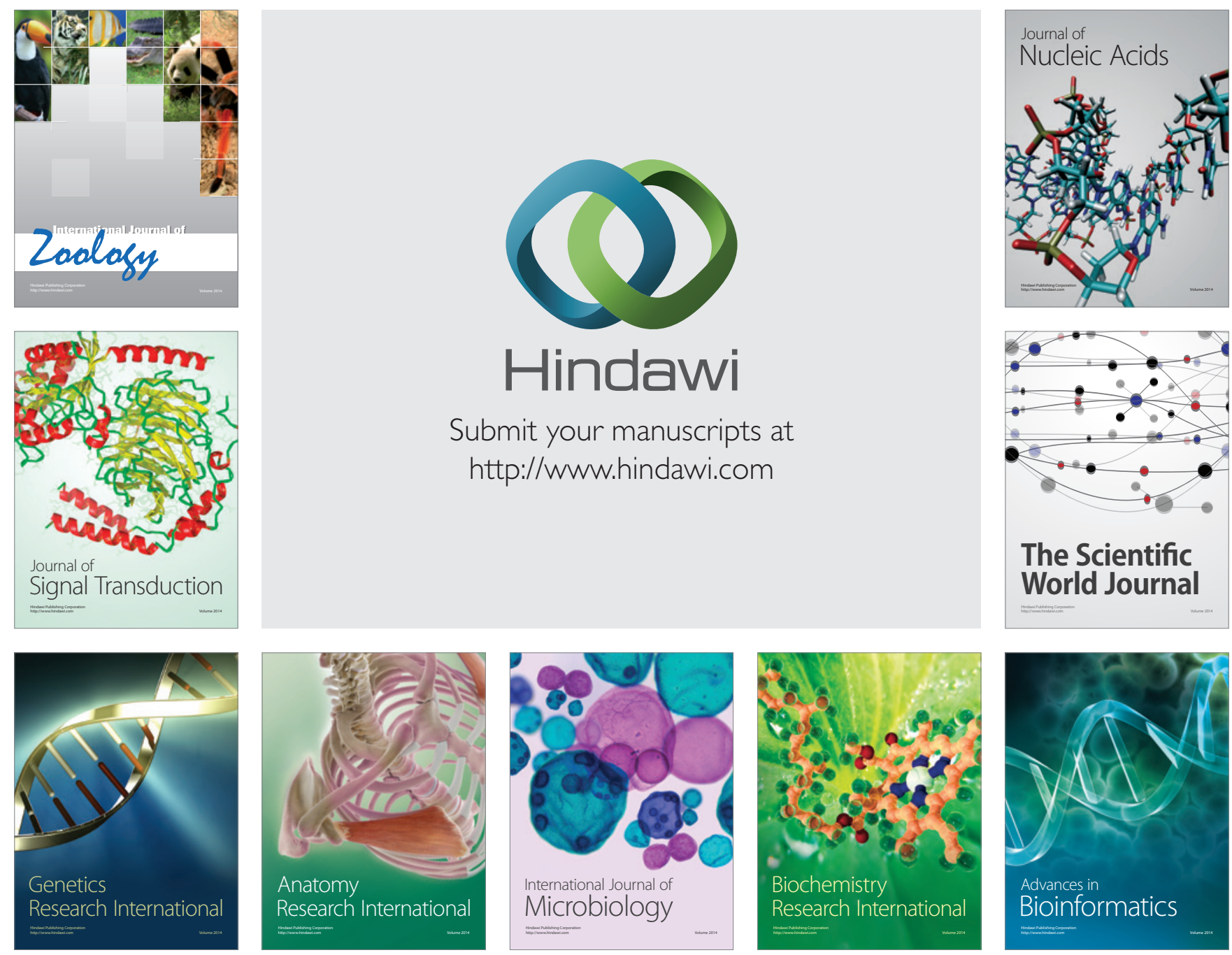

The Scientific World Journal
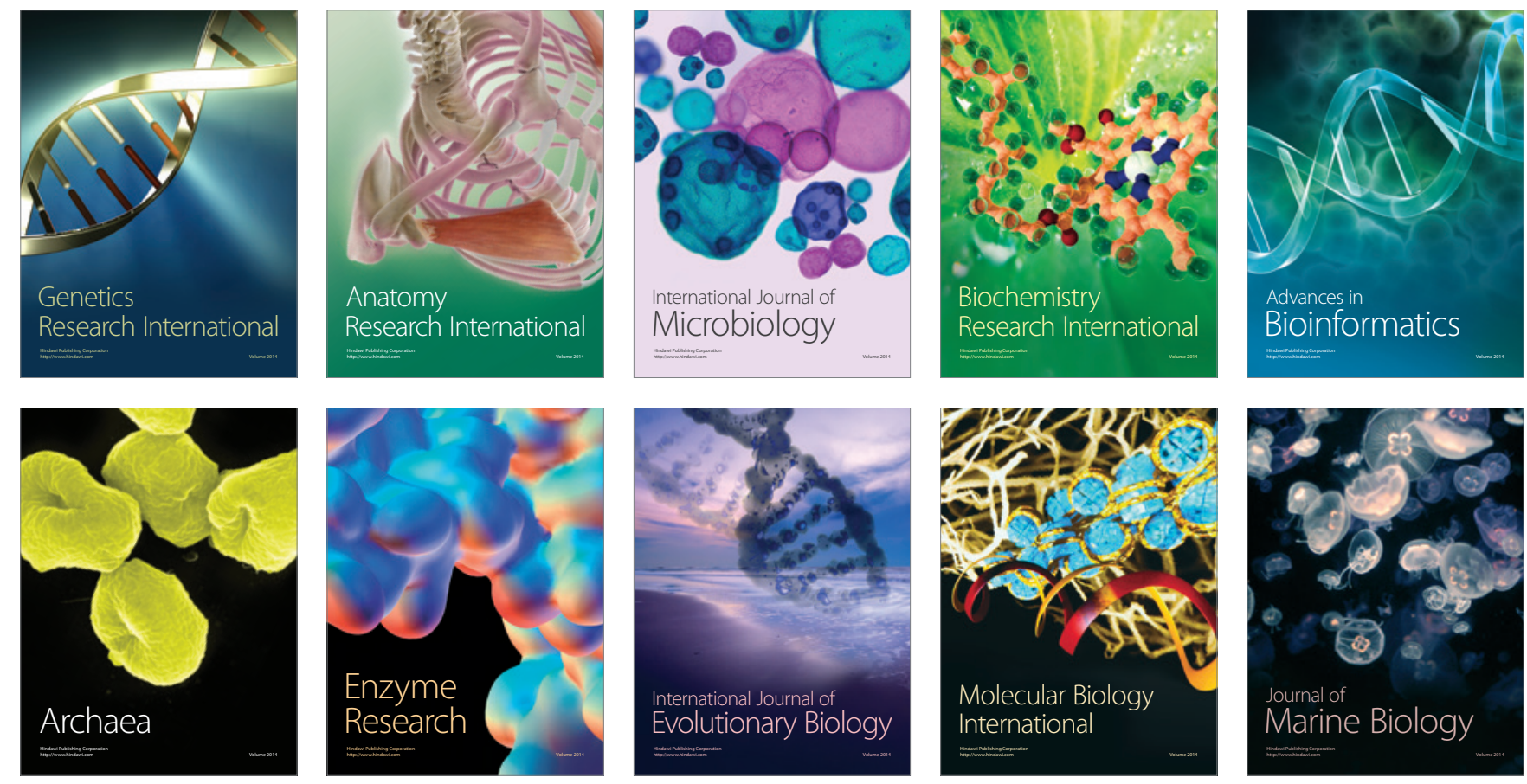